\title{
Reflections on the Psychotherapy of a Patient with Multiple Personality Disorder
}

\author{
David Fink, MD \\ Institute of Pennsylvania Hospital, Philadelphia
}

Follow this and additional works at: https://jdc.jefferson.edu/jeffjpsychiatry

Part of the Psychiatry Commons

Let us know how access to this document benefits you

\section{Recommended Citation}

Fink, MD, David (1987) "Reflections on the Psychotherapy of a Patient with Multiple Personality Disorder," Jefferson Journal of Psychiatry. Vol. 5 : Iss. 1 , Article 5.

DOI: https://doi.org/10.29046/JJP.005.1.003

Available at: https://jdc.jefferson.edu/jeffjpsychiatry/vol5/iss1/5

This Article is brought to you for free and open access by the Jefferson Digital Commons. The Jefferson Digital Commons is a service of Thomas Jefferson University's Center for Teaching and Learning (CTL). The Commons is a showcase for Jefferson books and journals, peer-reviewed scholarly publications, unique historical collections from the University archives, and teaching tools. The Jefferson Digital Commons allows researchers and interested readers anywhere in the world to learn about and keep up to date with Jefferson scholarship. This article has been accepted for inclusion in Jefferson Journal of Psychiatry by an authorized administrator of the Jefferson Digital Commons. For more information, please contact: JeffersonDigitalCommons@jefferson.edu. 


\title{
Reflections on the Psychotherapy of a Patient with Multiple Personality Disorder
}

\author{
David Fink, M.D.
}

Historically, the diagnosis of Multiple Personality Disorder (MPD) has generated curiosity, fascination, skepticism, and disbelief. From the first reported cases in the early nineteenth century, controversy has abounded about the plausibility of the many dramatic manifestations of the illness, its pathogenesis, and appropriate approaches to its treatment (1). From the midst of scientific controversy and debate, a more refined conceptualization of the illness is being developed, particularly since the recent inclusion of the diagnosis in DSM-III (2). Noteworthy among these advances are the theories of pathogenesis described by Kluft (3), and Braun and Sachs (4) which emphasize a prerequisite biological dissociative potential in combination with extreme environmental stress, and Speigel's (5) formulation framing MPD as a post-traumatic stress disorder. Despite these advances, many long rejected and scientifically invalid notions about the illness continue to play a part in the clinical assessment and treatment of MPD. Misinformation has led to delays in accurate diagnosis. A recent study has shown that the average length of time to reach the diagnosis of MPD is 6.8 years (6), with preliminary diagnoses ranging from schizophrenia to borderline personality disorder. The use of hypnosis as an adjunct in both diagnosis and treatment of multiple personality disorder has further complicated the picture, inspiring questions about the role of suggestion and the possibility of an iatrogenic etiology. One assumption has been that MPD is the unfortunate creation of an overzealous psychiatrist engaged in a folie à deux with a highly suggestible patient. These questions and concerns have clear effects on the treatment and management of patients diagnosed with MPD as well as with the other DSM-III Dissociative Disorders.

As a medical student and subsequently as a resident, I have had occasion to work with MPD patients and have been struck by the many complex attitudes and emotions these patients inspire. When I was assigned to admit Ms. S to our unit, I found myself in the curious position of having to sort out the many questions raised in discussions with colleagues. As one interview grew into many and my questions multiplied, I sought the supervision of Ms. S's attending

The author would like to gratefully acknowledge Dr. Richard Kluft for offering him the opportunity to work with this patient and for his continuing supervision. Dr. Fink is a second-year resident at the Institute of the Pennsylvania Hospital, Philadelphia, Pennsylvania. 
psychiatrist, who had considerable experience with MPD, and under his direction, began seeing the patient in both a joint and individual psychotherapy. I would like to offer a few observations about, and particular incidents from, the first six months of our clinical work, since I believe many residents approach patients with MPD with similar doubts, questions and curiosity that I have known.

The first interview took place in Ms. S's room. She is a young, gaunt, 34-year-old woman with attractive features and short cropped hair. During this interview, she sat protectively on her bed with her legs drawn to her chest and her arms around her knees. She appeared sad, anxious, and fatigued, but was pleasant and engaging, smiling socially on occasion. She said she had been hospitalized because she was unable to control strong impulses to harm herself. She expressed fear, shame, and embarrassment at these losses of control, denying any hallucinations or delusions, but reporting difficulty concentrating and the inner experience of "a civil war going on inside me." She denied thought insertion or withdrawal, but felt that she experienced "other presences" and at times was influenced to act, think, or behave in accordance with "their wishes." She described memory losses during which she "lost time" when "others" were out. Despite the disturbances of long-term memory, she functioned without deficit in short-term memory, and was able to concentrate and attend. She seemed to be of superior intelligence and was well able to think in the abstract.

Although she was unclear why she was having her present difficulties, she revealed a history of paternal sexual abuse that continued into her late teens; she described this as the reason for her chronic emotional difficulties. She also reported that she had been "unaware" of this abuse until the age of 29 , when she had become deeply depressed and began "impulsively" cutting herself on a daily basis. Since that time, she has been in intensive individual psychotherapy two to four times per week and has had multiple psychiatric hospitalizations. She has had a wide range of medication trials with major and minor tranquilizers and an array of antidepressants, including both tricyclic antidepressants and monoamine oxidase inhibitors with a consistently poor response. At the time of this admission, she was receiving $0.5 \mathrm{mg}$ of alprazolam every six hours for severe anxiety.

In our first few sessions, she cautiously described details of her sexual abuse. She also made veiled hints about her dissociative episodes and her experience of multiple personalities. Interestingly, she was wary and voiced concern about whether I believed in the validity of her illness or whether I thought it was a "manipulation." Her questions seemed to derive from her feelings of being perceived as "a freak." As I had only heard halting descriptions of her dissociative experiences, I did not know what to make of them. I did know that I experienced our interaction in the initial interviews as genuine. Her history, though extreme in the degree of abuse she described, was not presented in an 
overly dramatic manner. In its daily elaboration, it seemed increasingly credible.

In our fifth session, Ms. S had a sustained dissociative experience in which she underwent an apparent alteration of the executive control of the body. In the middle of a description of her family history, in an attempt to explore a traumatic childhood memory, she developed a severe frontal headache which increased in intensity over several minutes until she began to clutch her forehead. She described a "great pressure ... someone was pressing to get out." Upon my inquiry, she said that this was often how other personalities made their presence known and expressed their need to be recognized. I asked her if allowing that personality to express itself would relieve her physical discomfort; she acknowledged that often it would. I asked her to sit back and close her eyes, and invited any personality who had pertinent information to come forward. There was then a sudden change in Ms. S. The most striking observable effects were in the attitude of her body. She shifted from her tightly "drawn in," knee-to-chest, huddled position, to a more open posture with legs extended and loosely crossed at the ankles. She sat upright with her head held back and slightly cocked, and began to run her right hand through her hair and twist it around her fingers. Her countenance became less sullen and her "mask of shame" was exchanged for a bold, wide-eyed confrontational gaze and a sarcastic, wry half-smile. Her speech was no longer quiet and staccato, but strong and direct with full volume and normal prosody. Beyond the dramatic change in her bearing and appearance, the history she told revealed a different point of view and attitude towards the events we had been exploring before this second personality assumed control. The new alternate personality (alter) defiantly explained that she had been the one to endure the brunt of the particular experience described and that, in fact, she always seemed to be "caught in that role." Her emotional response to the trauma, in contrast to the initial personality's fear and depression, was fatalistic, but she was proud of her ability to endure adversity. This second personality presented bits of history from her point of view for a good portion of the session, revealing a richly elaborated sense of self. As the end of the session approached, I thanked her for coming forward and offering her point of view and invited her to return at a later time. I then asked her to close her eyes, and suggested that she "step back" so that the first personality might again "come forward." After a number of seconds, during which the patient appeared to be in a trance, all visible characteristics previously described reverted to those of the original alter.

It is difficult to convey the shock I felt during and immediately after this initial switching of personalities. Unquestionably, something quite dramatic and profound had taken place, an apparent transformation of body and mind. In the face of this very real-seeming event, I found many of my earlier preconceptions about MPD to be inadequate, and I began to reassess the "credibility" of the illness from a new point of view. In the weeks and months of therapy that 
followed and as switches of executive control of the body occurred on a regular basis, my attitude about this unusual psychopathologic process developed in steps-from curiosity to uneasiness to a gradual understanding of Ms. S's fragmented ego and her experience of rigidly divided, unintegrated aspects of the self. I began to see this as her response to overwhelming physical and psychic trauma.

Reflecting back on the early weeks of therapy, I am aware of both the feelings of curiosity and trepidation the dissociative episodes engendered in me. I found myself feeling unsure how to therapeutically use, divert, or manage switches of executive control as they occurred. My initial fear was that with personality switches, Ms. S would act in a dangerous or destructive way that I would be unable to control. The element of the unknown was unsettling-i.e., I have a relationship with an individual at this moment, I know enough about her to gauge both her safety and my own, but how will that change if she no longer experiences herself as herself but as someone else? Unlike more conventional clinical situations in which ground rules and guidelines for the therapeutic situation are implicitly or explicitly defined and agreed upon as therapy begins, there was no indication that the frame of therapy or assumptions about the working relationship held by one personality would apply to any other. This concern about my lack of control in a new and unfamiliar situation was initially focused on the issue of reestablishing the pre-dissociative state-would she cooperatively return to her "former self"? This, gradually over time, became framed as a larger issue: the patient's experience of being out of control and unable to maintain and rely on a unified sense of self. I came to better understand my initial fear in the context of the transference relationship. The patient's concern, “I don't have control over myself and need you to control me," was joined with my omnipotent countertransferential fantasies that I could or should be able to do so.

In fact, the patient's cooperation was evident in the facility with which she responded to simple suggestions concerning changes of executive control over her body. From the outset, Ms. S underwent personality switches without formal hypnotic induction, but with simple support and the acceptance that it was safe for her to "change." In subsequent sessions, as different alters presented themselves, my overriding concern for safety in the therapeutic situation gave way to the understanding that each aspect of the self came forward in an attempt to use therapy to achieve relief from its idiosyncratically perceived and experienced emotional burden. In this severely traumatized individual, each personality carried the emotional stigmata of sexual abuse and only cautiously revealed itself for fear of incurring further injury. Clearly, our fears of the unknown were mutual and reciprocal, and, as in more traditional clinical situations, ideas, fantasies, and emotions surfaced in the context of our growing therapeutic relationship. Each personality wanted to be accepted and understood by the therapist. If many alters rejected or undermined the aims of therapy, each 
sought the gratification of being able to relate to another, a bridge back from its isolation.

Beyond the initial few weeks of therapy, during which "introductions" were done, the therapeutic work became more traditional. I came to understand the switches of personality as guides to areas of unconscious conflict, functioning dynamically across psychic structures. Frequently, transitions of executive control would happen spontaneously in the form of emerging memories or as defensive responses to memories which involved overwhelming affect. For example, when one of the personalities who represented a very early childhood experience was "reliving" a sexual assault, a personality switch occurred in which another personality served as protector, assuming the first personality's burden of pain. This kind of switching was common and revealed the way that the personalities had functioned in the original genetic situation, offering clues to the possible reasons for their creation. Alter personalities tended to present stereotypical views, responses and needs, and to a degree formed predictable, stable intrapsychic constellations which served as grist for the psychotherapeutic mill.

As I gained knowledge of the functions that dissociation and the different personalities served, I began to develop a better appreciation for subtle signs of the effects of emergent or conflicting alters. Frequently, somatic expressions served as important indicators of intrapsychic conflict experienced by the patient as tension between dissenting alters. I have already described one instance of this phenomenon in the sudden intense frontal headache which signaled another personality's strong wish to "gain access." Other examples occurred when one body part acted inconsistently or incongruously with other body parts. The body, for example, could be resting quietly while one foot tapped rapidly. Similarly, the hands at one time during treatment would periodically assume a scratching or tense clawing position and either begin to claw or simply maintain the position without action. When questioned about these incongruities, the patient felt that they were not under her control, nor could she explain why they persisted. She described a sense of anxiety, foreboding, or threat which she related to her lack of control over her body and the "awareness of another personality's presence." In this particular example we discovered that her hands were in a clawing position because she wanted to scratch her eyes so as not to have to "see" a particular memory recalled. I understood this behavior, on one level, as one personality's defensive response against material surfacing in therapy.

Another example of somatic expression of inner fragmentation was the frequent division of the body into visual planes. This situation arose repeatedly in therapy when a difficult contract or decision was required of the patient, particularly when it concerned a contract against self-harm. On one occasion, Ms. S obscured half of her face behind her hands and responded to a set of questions. When asked if the response was unanimous or if there were strong, ambivalent, opposing feelings, the obscured part of the face revealed itself and 
expressed the dissenting view. Another dramatic instance of somatopsychic interaction occurred during a period of crisis when several alters had strong conflicting needs and were vying for control of the body in order to express themselves. The patient experienced a profound lack of psychic control and was switching personalities freely. Concurrently, she developed a marked impairment of motor control with a striking apraxic gait. It seemed as if her lower extremities could not function synchronously, but rather acted independently, resulting in her lack of coordination. This symptom abated after several days as the intensity of her intrapsychic crisis diminished.

From my work with Ms. S over the last six months, I have clarified and reevaluated a number of my original questions and preconceptions about MPD, at least in regard to this particular case. Foremost among these was the diagnostic question about borderline personality disorder. While this patient uses the primitive defense mechanism of dissociation, she does not employ "splitting" in the way a borderline patient classically does. There has been no all-good, all-bad dichotomy. She does not use projection or projective identification, idealization, or denigration to a pathological degree. To a great extent, she contains rather than projects her emotional pain and ambivalent feelings. In our therapy, she has respected boundaries and limits. Thus, while she demonstrates many behaviors common to patients with borderline personality disorder, and while many MPD patients may well demonstrate borderline defense mechanisms, this individual does not have a borderline character structure. Similarly, concerning the diagnostic question of psychotic illness, this patient has had a number of quasi-psychotic experiences, specifically illusions, but these have been brief and only dimly recalled by the primary personality. It has been my experience that in these instances, another personality can elucidate the details of the poorly perceived event. Even during these episodes, the primary personality is often able to maintain reality testing and recognize the occurrence of an ongoing dissociative experience or a switch of executive control.

No definitive statement can be made regarding the concern of suggesting MPD or of initiating a proliferation of personalities from a resident's work with one patient. This patient, however, was far from suggestible. My therapeutic interventions were carefully considered and not summarily accepted by Ms. S. I found that bad interpretations reliably fell flat, premature interpretations were rejected, and interpretations given at the wrong cognitive level for a given personality were either misunderstood or ignored. The many separate personalities had integrity and knew what they believed.

As our work has progressed, many new questions have arisen. These are now less concerned with the unique "structural" aspects of the illness or the initially startling and unfamiliar use of dissociation as a defense, and are now more concerned with the therapeutic complexities and emotional rigors, for both patient and therapist, evident in the long-term treatment. The material which has emerged in the course of therapy has contained repeated description and reexperiencing of sexual trauma and abuse. The power of the incestuous 
trauma remains overwhelming. One ongoing struggle in the treatment is to balance countertransference reactions so as to not react in an aggressive or rejecting manner on the one hand, or in an over-protective manner on the other. Similarly, in a patient who has been harshly trained to be compliant and submissive, how does one avoid a sadomasochistic therapeutic relationship? At this point, it is my impression that the nature and extent of the trauma endured by the patient, and her continual reworking of that trauma, profoundly affect staff members and that our work with her has required ongoing vigilance to keep negative countertransference responses in check.

In the six months I have worked with Ms. S, I have found that much of the cautious and skeptical advice given to me by clinicians unfamiliar with MPD reflects longstanding and widely-held beliefs, but is not consistent with clinical experience. This is not to imply that I feel I understand the condition. I have found more questions than answers; I am puzzled by this patient's many contradictions. As I become increasingly familiar with her use of dissociation as a defense, I continue to be struck by the strange and unpredictable turns her symptoms take. Recognizing that her primitive pathological coping skills are, in large measure, proportional to the magnitude and extent of her protracted incestuous experience, these realities remain difficult, if not impossible, for a therapist to completely understand. With increasing knowledge and understanding, I have a developing respect for this woman's endurance in the face of such profound emotional pain.

I realize as I finish this personal record how unfinished my thoughts are about this patient and her disorder. The process of understanding and treatment is ongoing as I continue to see Ms. S regularly in outpatient psychotherapy.

\section{REFERENCES}

1. Ellenberger HF: The Discovery of the Unconscious: The History of Evolution of Dynamic Psychiatry. New York, Basic Books, 1970

2. American Psychiatric Association, Diagnostic and Statistical Manual of Mental Disorders, Third Edition, Washington, DC, APA, 1980

3. Kluft RP: Aspects of the treatment of multiple personality disorder. Psychiatric Annals $14: 51-55,1984$

4. Braun BG, Sachs RG: The development of multiple personality disorder: predisposing, precipitating, and perpetuating factors, in Childhood Antecedents of Multiple Personality. Edited by Kluft R. Washington, DC, American Psychiatric Press, 1985

5. Speigel D: Dissociation, double binds, and post-traumatic stress in multiple personality disorder, in Treatment of Multiple Personality Disorder. Edited by Braun B. Washington, DC, American Psychiatric Press, 1986

6. Putnam FW, Guroff JJ, Silberman EK: The clinical phenomenology of multiple personality disorder: review of 100 recent cases. J Clinical Psych 47:285-293, 1986 